\title{
Voice Handicap Index-10
}

National Cancer Institute

\section{Source}

National Cancer Institute. Voice Handicap Index-10. NCI Thesaurus. Code C120505.

A 10 item self-assessment for adults to evaluate a patient's perception of their voice and the effects of their voice on their life. 